\title{
Design thinking: Project Portfolio Management and Simulation - a creative mix for research
}

\author{
Saeed Shalbafan ${ }^{1}$, Elyssebeth Leigh ${ }^{1}$ \\ ${ }^{1}$ University of Technology, Sydney
}

\begin{abstract}
${ }^{1}$ Abstract. This paper takes de Bono's explanation of 'design thinking' as the starting point for a report on a doctoral research project that began with a conventional 'why?' question, and then, instead of looking for an 'explanation', chose to look forward in time to establish an understanding of 'how to' think differently about a recurring problem. The catalyst for this work was observation of otherwise competent managers making desperately wrong decisions when good decision making was crucial to their company's future. The initial choice to 'look forward' when designing the research strategy was made well before there was a clear understanding of what was being observed. Given that trajectory, this paper explores the process by which a simulation was created and then used in conjunction with a comparatively new approach to data collection.
\end{abstract}

Keywords: Design thinking; Project Portfolio Management; Cynefin knowledge domains; sense making in complex contexts

\section{Introduction}

It all began with a series of increasingly worrying decisions that seemed to be at odds with what was otherwise known about the capabilities of the decision makers. The context was a project portfolio management (PPM) office which was thrown into chaos as the events of the Global Financial Crisis (GFC) began impacting on the rate of business growth in Australia. A comparatively new member of the PPM team was expecting to see considered and thoughtful attention being given to the quality of decision making as conditions worsened. Instead attention to decision making seemed to be haphazard and lacking in the kind of thoughtful focus needed in times of stress. As time passed the idea of researching the nature of what had happened emerged as a doctoral research proposal. The initial questions were focused on why things were not better managed and the research began with that in mind. At first the intention was to conduct research directly within the context of what had been observed. However,

${ }^{1}$ Explanation looks backwards and design looks forward [1]. 
those poor decisions had proved costly enough that the observer, along with other staff, was eventually out of work, as the number of projects dwindled and there was no longer a project portfolio office to research. Although that seemed a death knell for the research, it took it in an entirely new and creative direction. Instead of asking 'why' the decision making was not of a better quality, the research focus shifted towards understanding how to help others, facing similar situations in future, make better decisions by looking forward rather than back. Edward de Bono [1] noted that 'explanation looks backwards and design looks forward', and since it had become impossible to seek explanations about those past events, the opportunity was emerging to apply the painfully garnered observations to the task of developing an understanding of 'how to' think differently about a recurring problem.

This paper reports what happened when the focus of the question changed. Design thinking came to the fore, and a unique simulation was designed to assist in researching the process of thinking differently about an unfamiliar situation. The initial thought had been to use an existing simulation game to simulate the context of PPM decision making. The simulation was to be the replacement for an organisationally based case study. As organisational life cycles are becoming shorter and less certain, it made sense to create a similar environment that would remain under the researcher's control for studying decision making. Lack of access to confidential information about those prior strategic decisions was another issue supporting the idea of using simulation. The aim was to create opportunities for participants to act 'as if' decision makers in a role play context while allowing the observer to understand how decision makers make decisions. Key challenges emerging from these initial thoughts, included the extent to which existing designs would be a fit with the context of decision making in PPM, while providing sufficient relevant rich data for analysis. Each of these concerns were addressed in the process of developing a more creative view of the presenting problem which, in turn, led to the design of a unique simulation for use as the research instrument.

\section{The background}

The observer/researcher had started working as a skilled migrant in a new country. The homeland with its rich history for addressing complexity and uncertainty was a place where, to survive, people must be forward thinking in their day-to-day life. During the observer's social learning in childhood each plan was understood to need a plan B to respond to unexpected events. Having arrived in a country famous for its luck in policy making and blessings for its rich natural resources, this approach did not seem to be much of importance for senior managers. Observation of local management practice began to reveal indicators of an absence of a holistic view about resources utilisation, as well as poor/delayed responses to the need for setting strategic direction - both indicators of problems in senior management decision making.

The crisis occurred for the observer's employer when funding limits were suddenly imposed on a major project. The corporation was derailed from its flourishing practice, and the business unit absorbed into other units. The company vanished from the market within three years. The observer's initial re-action had been a desire to 
help senior management teams avoid further such crashes arising from poor decision making. The lack of a holistic view, and an absence of tools to promote its benefits, had been identified as two factors indicating the need to work on a framework for implementing a better approach to PPM in the corporation.

Discussion with senior managers, and reviews of publications, created a project portfolio road map focusing on resource utilisation and timelines as the core of an exercise to improve efficiency in regard to selecting and prioritising projects to align with available resources [2]. This was to support a single case study for the $\mathrm{PhD}$ project and had, indeed, begun to show its value. The sudden, unexpected market changes, coupled with growing competition and side effects of the GFC in 2008 [12], forced the company board to re-shuffle the organisation chart, downsize and eventually sell the business within a very short period. The observer was a new comer to Australia, and the employer had been the only reliable source of research data, as well as a good context for researching use of a multiple projects structure. However, as the changes took effect the research shifted from a case-study to an entirely new approach. The resulting journey let to the design of Hooshmand-1 - a bespoke simulation designed for the purpose of researching the problem, which has now been adopted for use in education programs in Australia and overseas. The research also changed focus, producing a forward-looking, rather than a backward-facing research dissertation, as well as a number of intermediate research papers (e.g. Shalbafan, Leigh et al. 2015).

\section{Design process}

While design thinking, as a term and a method, is still somewhat contested, it is generally considered to be method allowing practical, creative exploration of problems leading to solutions that are 'emergent' rather than pre-defined. Its use encourages consideration of both present conditions and future needs and interests. Design thinking may produce a number of alternate solutions, rather than a single 'first best fit' outcome. In this regard it is fair to say that there were several options available at the beginning of the research, yet none of them were so obvious as to automatically rule out any of the others. This led to a time-consuming, and at times painful, series of action learning cycles. Each of these had three distinct goals. The first was to identify key features needed in a simulation to serve the emerging purpose of the research. The second was to identify whether any existing designs might meet these criteria. The third was to work out the logistics for making use of whatever design proved to be most suitable. Two key underlying assumption were, first that the data-collection aspect of the research would use decision makers already employed in senior levels of management with experiences in a number of different industries; and second, that the action would explore how they made decisions when facing the kind of unexpected events commonly called 'Black Swan' episodes [19]. 


\subsection{Trialling existing designs}

A number of diverse designs were identified and some were trialled with volunteer participants. Key and essential features needed for developing a successful research tool, were unclear at the beginning, and each iteration brought only a very rough approximation by the end of each trial. Fragments and evidence to support the ideal simulation were collected and analysed throughout the cycle of trials as the process began helping to uncover what an effective simulation design - that would be fit for purpose - could look like.

Each trial took two to three months for completion beginning with identification through to enactment, examination of outcomes and conclusions about what needed to be sought next. There was a clear 'tipping point' that shaped much of the ensuing process during the first trial of a role-play simulation which had been originally designed for exploring communication and decision making in academic settings. This was called WipWap and was the outcome of a Master research project [11,12].

WipWap was re-crafted to compress time to create a learning environment for volunteers to assess pre/post knowledge of decision making in PPM. The game provided a good model of a setting in which to engage participants in group decision making, a factor which informed the final design of Hooshmand-1, but was otherwise deemed not fit for purpose. Key lessons emerging from enactment this simulation, included the observation that cause-and-effect relationships and linear/non-linear behaviour could not be understood by participants at the same time as their activity was causing the process to slip into chaos. This was the tipping point that changed the research question from 'why?' to 'how?'

Keeping in mind that the research aim was to study PPM decision making in complex situations, with the goal of supporting effective strategic direction setting, the intention was to explore how to implement PPM as a vital contributory mechanism. An anticipated outcome would be to provide corporations with guidelines to reduce the chance of failures in executive decision making. After this first challenging simulation, conducted with volunteer participants, it became obvious that many were unable to make a connection between their knowledge of PPM and their performance in the simulation. This was interpreted as an indicator of the absence of consensus on a definition of PPM as included in organisational structures. This led to abandoning the intended pre-test/post-test strategy for assessing participants' understanding of the Project Management body of knowledge. Instead, the focus shifted to a consideration of whether self-proclaimed 'rational decision makers' are making decisions based on their emotions. Thus emerged the second tipping point contributing to the final design of the new simulation and its associated research questions.

After observing the first iteration of this simulation, the observer/researcher realised that many beliefs and assumptions about the linear behaviour of decision makers, and the timing of associated actions, were not working well. It became clear that a different approach would be needed to create meaningful results for the research project. Analysis of these observations resulted in a shift to a research method that would involve moderating factors such as facilitation processes in the design of a simulation to help form a research study that would have some degree of control over the outcomes of participants' actions. 
The second iteration was a simulation game - AirPower2100 - developed for use in re-shaping decision making in regard to flight and maintenance schedules on a military air base [7]. Its design was diametrically opposed to that of the first trial. In this design, every action was followed by an instructor's permission to take the next action, so participants had far less freedom of action. It was played for one cycle of activity (the full simulation involves two cycles) to develop a sense of whether a conversion could be made from the original design for air force training, to an executive decision making simulation. The immediate conclusion was that the existing design could not support the kind of communications and freedom of decision making familiar to those working in the context of a PPM office. However, observing this enactment showed the value of including strict rules in the role play to achieve desired the objectives. This finding was central to the design of the facilitation process for use in managing Hooshmand-1.

\subsection{Encountering Cynefin}

Both simulations thus failed to provide an effective context for referencing theories relevant to PPM. Both also demonstrated aspects of the non-linear nature of decision making in complex problems. An additional problem was also emerging at this time the recruitment of volunteers was becoming more difficult than had been expected. This triggered a curiosity leading to investigation of the Cynefin framework [10] as a tool for studying decision making in complex situations.

The Cynefin model proposes that we encounter knowledge in three modes across five domains. Knowledge modes are either 'Ordered' (systematic and structured), 'Unordered' (complex, without pre-determined form) or 'Disordered' (without form or knowable structure). Within these modes the Domains are 'Obvious' and 'Complicated', in the Ordered mode, 'Complex' and 'Chaos' in Unordered mode, and 'Disorder' stands alone. Each Domain represents a way in which knowledge is received and responded to; individual capacity for awareness to context, impacts responsiveness to conditions in which we find ourselves.

The Obvious domain is the most familiar of the knowledge domains. We are usually comforted by the appearance of the orderliness of things, and prefer not to depart from it. Unless there is reassuring guidance. Such guidance usually comes in the form of 'expert help' to introduce us to the 'hidden order' - which is knowable and accessible - in the Complicated domain.

The comfort of these ordered modes is very different from the uncertainties of the 'Un-ordered' knowledge domains, where there are no absolute certainties. Konwledge in the Complex domain can be sought but is not readily evident. So there is much 'shuffling of feet' when conditions seem to be sliding away from our 'comfort zones'. However, if we plunge in, we become adept at the essential tasks of checking assumptions, and learning to 'probe' for meaning, developing a capacity for 'making sense of' what confronts us, and finding ways to manage unfolding events. There will be time, later, for reflecting on the quality of responses. The Complex domain necessitates reducing dependency on experts, and increasing proficiency at designing our own strategies and actions. Taleb's 'Black Swans' (ibid) may be found here, and also in the 'Chaos' domain - depending on their severity and impact. 
The Chaos domain is evidenced by an absence of causes, rules or guidelines for action. While, in truth there may be, they may not ever be fully understood - so we have a choice - flee, or take action to reduce the confusion. Life is often going to be chaotic, so becoming able to take action and make sense of what happens reduces the need to rely on someone else rescuing us from uncertainty. When we confuse Chaos and its opportunities with Disorder we may flee into denial and attack others (things and people) who seem to be causing the 'chaos'.

Finally there is the pivotal domain of 'Disorder' around which the other four are arrayed. As Cynefin is a conceptual model for thinking about knowledge, the positioning of 'Disorder' as the central pivot is not so much a tribute to its importance, as an indication of its potential for destruction. Disorder is to be feared. It is the name of all those nameless dreads that induce fear and cause individuals to flee to the known and 'safe' context of the Obvious, while failing to realise that uncertainty and 'Chaos' are merely learning tools with which to tackle a future that is forever unknown but always coming. An idea was forming about the possibility of creating case-based scenarios to replicate features of the chosen Cynefin domains. Of the five, the 'Complicated' and 'Complex' domains became central to creating a design incorporating two scenarios.

\subsection{Establishing Realism and Setting Parameters}

The process of developing a theoretical framework for a simulation is always challenging and the context needs to be finely tuned, if it is to be realistic. As part of the search for a framework the researcher interviewed a professor in PPM who had completed research using multiple case studies on the nature of uncertainty in PPM decision making. An exchange of ideas and information, with professor Yvan Pettit, provided great insight into existing research work on uncertainties and mechanisms for managing their impacts on decision making processes [14]. Discussion of those case studies helped to create fictional scenarios and refine the research questions into a more precise format.

The final design elements emerged through the opportunity to attend a classroom exercise for postgraduate students enabling observation of several factors allowing integration of key theoretical components into a simulation game. The exercise occurred after a lecture about PPM tools and their application 15].

On the first occasion the researcher attended the event to observe its operation. On the second occasion, the chance to participate with the students was taken up. The game included an embedded decision making process for project selection and introduced different methods of presenting data and the participants' judgements of the data [9]. This simulation included a short pilot to help participants become familiar with the objectives; while the main session was intended for individual participants to work out their solutions. All this was followed by a group discussion about the final agreed solution/s.

Participating with the students illuminated key aspects of theory in PPM decision making - including decision criteria, objective setting, and how individual judgements can be influenced by the presentation of information. This triggered the researcher/observer to extend this aspect of the design to the emerging simulation as 
an index with which to measure the dynamics of peoples' judgements while the decision-making environment is changing.

These experiences provided the features that together showed how to develop a promising design for a new game. This final step, enabling the transition from sense making of fragmented observations and cues, to use creative thinking and relying on intuition, proved necessary to achieve a successful outcome. Table 1 summarises the results of these experiences in relation to the development of the simulation Hooshmand-1.

\subsection{Assembling the Components}

Having decided to use Cynefin as a framework, the contexts for scenarios 1 and 2 of the simulation were constructed so as to resemble a Complicated and a Complex world. At this stage, the concept of a 'sense making process' was becoming available as a tool to understand complex problems and it was agreed that the SenseMaker software [17] was a suitable tool with which to analyse participant post-event narratives.

Table 1 - summary of thinking for different components of the simulation Hooshmand-1

\begin{tabular}{|l|l|l|l|}
\hline Data Description & Stream & Step & Collection/Presentation Tools \\
\hline Warm up game and briefing & Input & 1 & $\begin{array}{l}\text { A short game to make participants } \\
\text { familiar with each other }\end{array}$ \\
\hline Facilitated Simulation & Input & 2 & $\begin{array}{l}\text { Timer on Wall, Roles and Scenarios } \\
\text { (Papers) }\end{array}$ \\
\hline $\begin{array}{l}\text { Time of Completion, Value of } \\
\text { Decision, process of decision } \\
\text { making }\end{array}$ & Output & 3 & $\begin{array}{l}\text { Report Sheet 1/ Data for Time /value / } \\
\text { Consequences of decisions, consensus } \\
\text { on final decision }\end{array}$ \\
\hline $\begin{array}{l}\text { Facilitated Simulation + Real } \\
\text { Time Events }\end{array}$ & Input & 4 & $\begin{array}{l}\text { Timer on Wall, Roles and Scenarios } \\
\text { (Papers), Emergency Letters }\end{array}$ \\
\hline $\begin{array}{l}\text { Time of Completion, Value of } \\
\text { Decision, process of decision } \\
\text { making }\end{array}$ & Output & 5 & $\begin{array}{l}\text { Report Sheet 2/ Data for Time /value / } \\
\text { Consequences of decisions, consensus } \\
\text { on final decision }\end{array}$ \\
\hline $\begin{array}{l}\text { Short stories if individual/group } \\
\text { reflection }\end{array}$ & Input & 6 & Flip chart and sticky notes \\
\hline Recorded Audio- Video & Output & 7 & Facilitated Reflection \\
\hline Emerging Patterns & Output & 8 & Narrative analysis by using sense-maker \\
\hline
\end{tabular}




\subsection{Trials, Tribulations and Changes}

Table 1 summarises the thinking behind the different components of Hooshmand- 1 . Once these elements were in place, a set of draft materials was prepared for an initial pilot session. This first session had an estimated length of 4 hours - however it actually lasted 7 hours. The key lesson learned at this point, was about the essence of having a strong and clear - but short - verbal briefing to provide essential background information. On this first occasion everything was in writing, which proved to be a time-consuming mistake. The second observation was that participants enjoyed the interactive session at the end where they were asked to prepare a group presentation to the other teams, however this too, was very time consuming. As the aim was to engage senior executive managers in the simulation process, and it is self-evident that their time is scarce, there was a clear indication of the need to improve the design to ensure it held its sense of realism but was more time efficient.

The second pilot session began with a verbal presentation, but participants completed only one scenario because they ignored all the alerts for finishing on time and could not arrive at agreed solutions. A key improvement gained from this experience concerned the importance of enforcing good time management via the facilitation process. A bell alarm and countdown calendar were added to the space of the simulation to make time more tangible and create a sense of urgency in participants during the decision-making process. It was also decided to create a road map - as a source of key information - to give to the team leaders for use as they saw fit with their team members, so that all individuals could better grasp the information.

By this time, the facilitation process had been standardised through use of a simulation protocol, which was helping the researcher ensure there was minimum variation between multiple simulations, from a process perspective. The members per group was set at a minimum of three people per group, to ensure a balanced, but minimum level of, communications channels in favour of process efficiency. Introduction of a 'role rotation' was recognised as a valuable addition and included during the final stage of the design. This was introduced as an additional element and put into action between the two scenarios to avoid any sense of a negative bias on role performances. Figure 1 illustrates the completed simulation design for Hooshmand-1. Recruiting for participants was the next challenge, as professional people were only available after working hours and persuading them to participate was difficult. The key message emerging from this aspect of the research process was the importance of providing the opportunity for self-imposed challenges on individuals' decision making capabilities in uncertain conditions. The growth of complexity in business was a key driver encouraging people to come to the assessment lab and explore how they deal with unexpected and changing conditions. Hooshmand-1 has a number of embedded components including communications processes, group decision making and interactive dialogue to facilitate the process of sense making in two increasingly difficult scenarios where participants have only limited information available for arriving at final decisions. 


\section{Applying Hooshmand-1 to research PPM decision making}

Sa. Silva, Pedrosa et al. [15] state that simulations, games and challenges have common areas as shown in Figure 1. Their Venn diagram shows that depending on the designer's desire to use each/any of these three concepts, four additional areas may be identified in the common/overlapping areas between each pair of the three components.

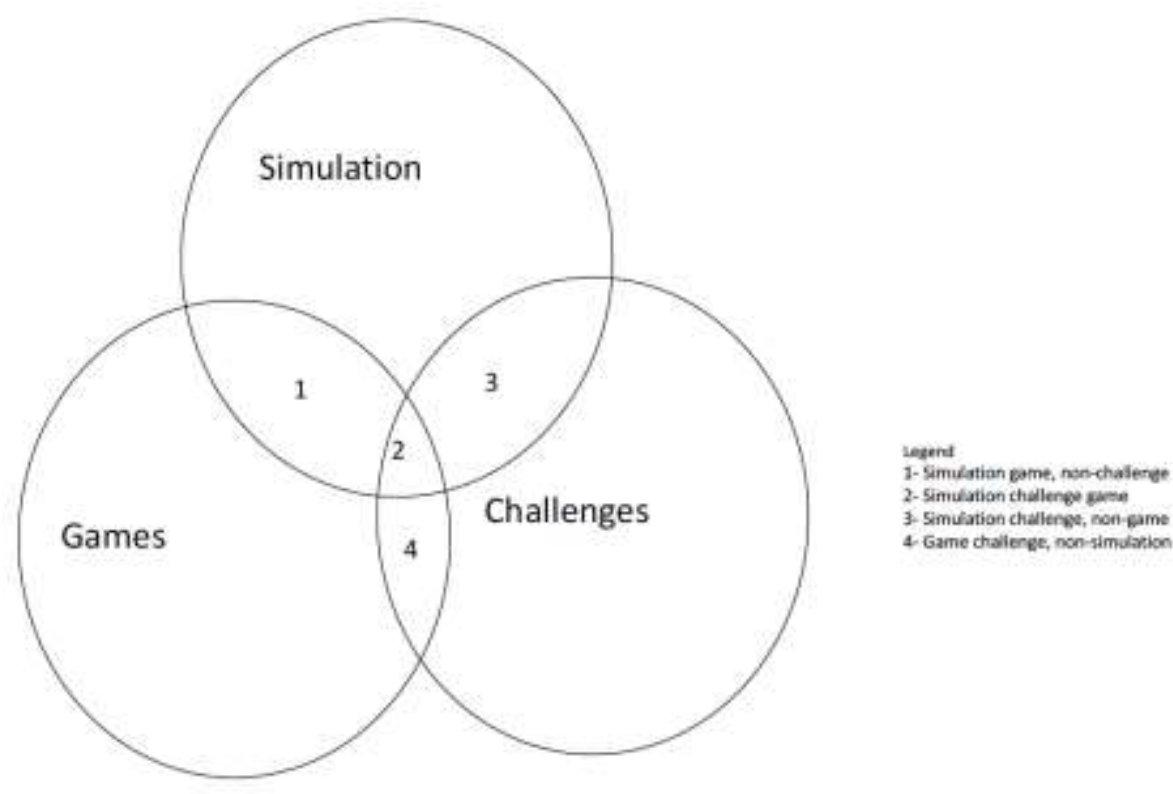
66)

Figure 1. Simulation, challenges and games relationships (Sa. Silva, Pedrosa et al. 2011, P.

Simulation game, non-challenge engages participants to interact with an imitation of a system based on real world settings within defined rules of a game. According to Hussein [4] there is still little research on the use of simulation games for learning about/exploration of project leadership for individuals responsible for identification and execution strategies in relation to projects in the early planning phase. Hooshmand-1 can be categorised as a 'simulation challenge game' in this model, since it generates an open-ended simulation of project portfolio management for research purposes, in which participants play designated roles without there being a defined resolution at the end [17].

Four runs of Simulation Hooshmand-1 with 33 participants has proved this to be a successful design that creates space and time for participants to learn through an interactive process of decision making. It also exposes individuals to deeper awareness of their sense making skills as well as factors influencing group decision making. 


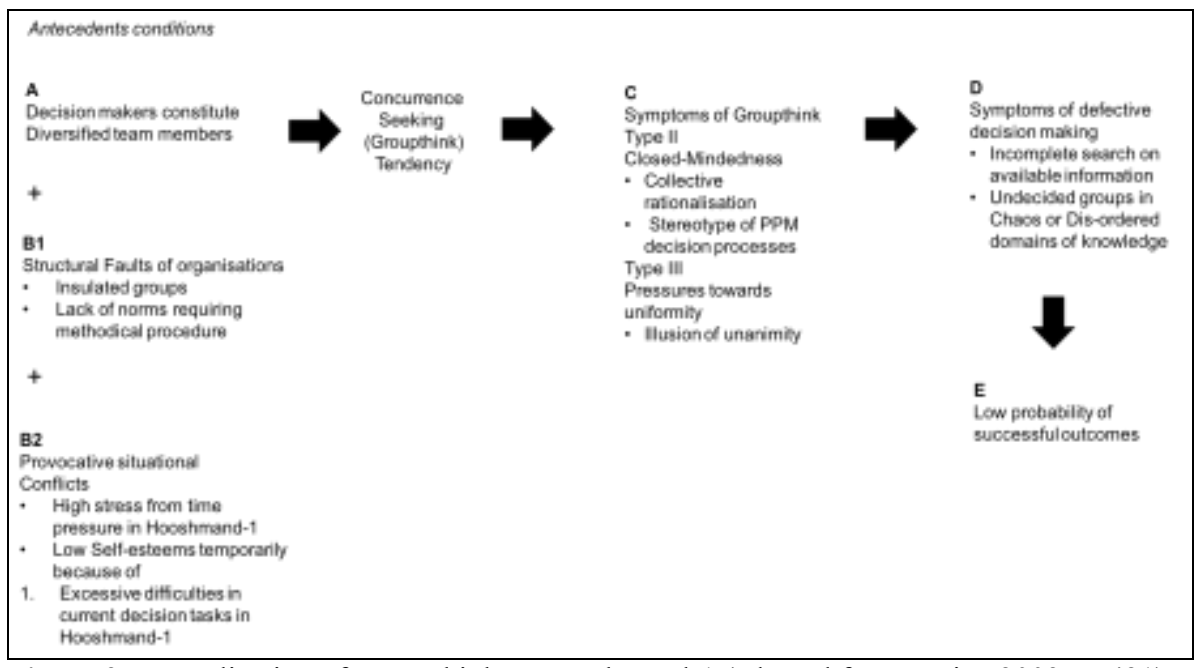

Figure 2 An application of Groupthink to Hooshmand-1 (adapted from Yetive 2003, p. 421)

As the research process evolved it became evident that the concept of 'Groupthink' $[5,6]$ could contribute an explanation of the causes for misjudgements and poor decision outcomes. Figure 2 presents an analysis using aspects of the concept of 'Groupthink' and its impact on decision (especially defective ones) based on evidence observed in four simulations. Antecedent conditions are listed at A, B1 and B2. Decision makers were from different group without any joint experience prior to the simulation. A key organisational fault emerged in the form of the insular way in which groups worked in isolation from each other, although this was not forbidden by the rules of the simulation. An absence of pre-agreed norms meant that participants had to decide how to work together and make decisions. None chose to do so. Conflicts arose because of a) imposed time pressures, b) increasing complexities and difficulties of working in an unfamiliar (although representative) context, and c) the PPM tools introduced in Context 1 and Context 2.

Symptoms of Groupthink indicate problems can arise such categories as - 1) overestimation of capability, with an illusion of invulnerability, II) closemindedness that can suffocate critics of an apparently, group-collective position, and III) pressure to uniformity - manifesting as self-censorship [19]. The symptoms of Groupthink manifested during the simulation showed up as type II and type III - especially rationalisation and stereotyping of the PPM process.

Participants' feedback, from the four completed events, has confirmed that the design of Hooshmand-1 provides a context 'close enough' to their real-world experiences. 

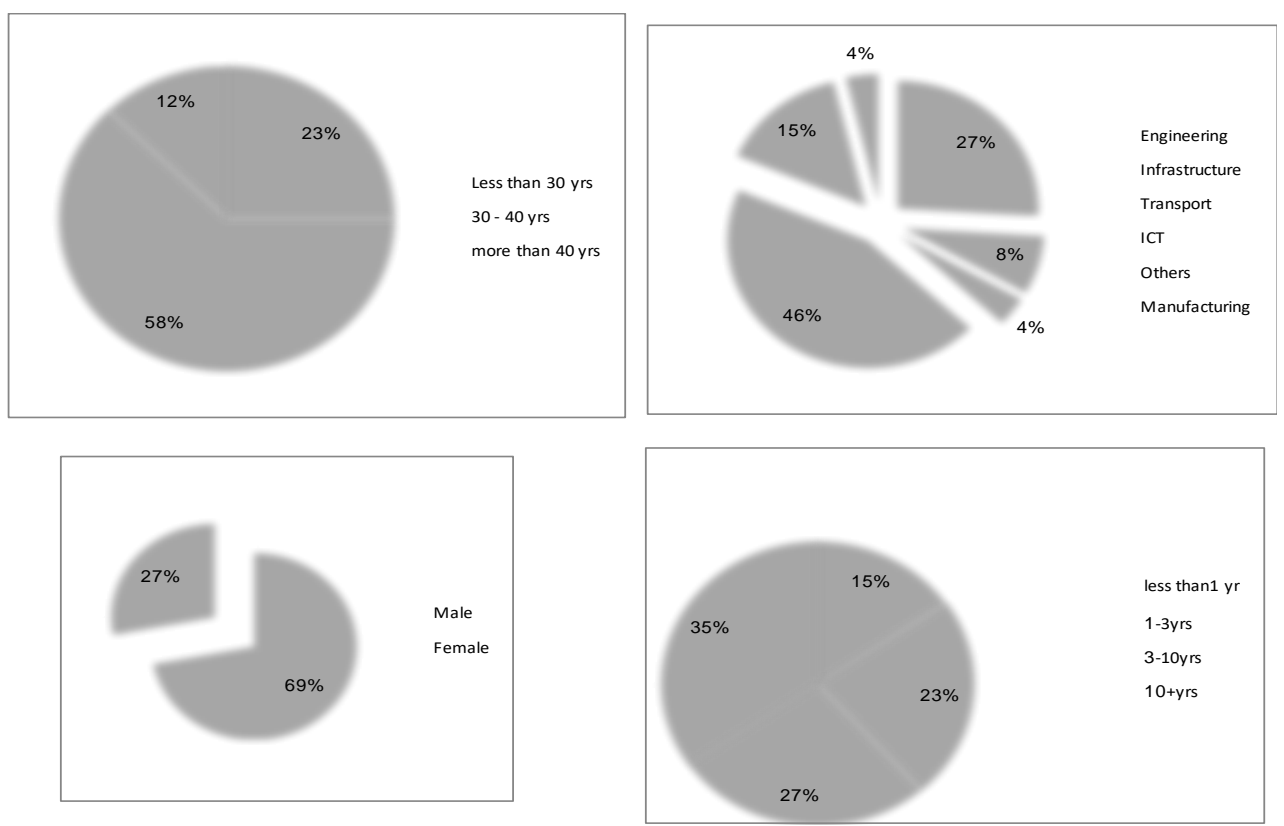

Figure 3 - Demography of participants in 4 trials of Hooshmand-1

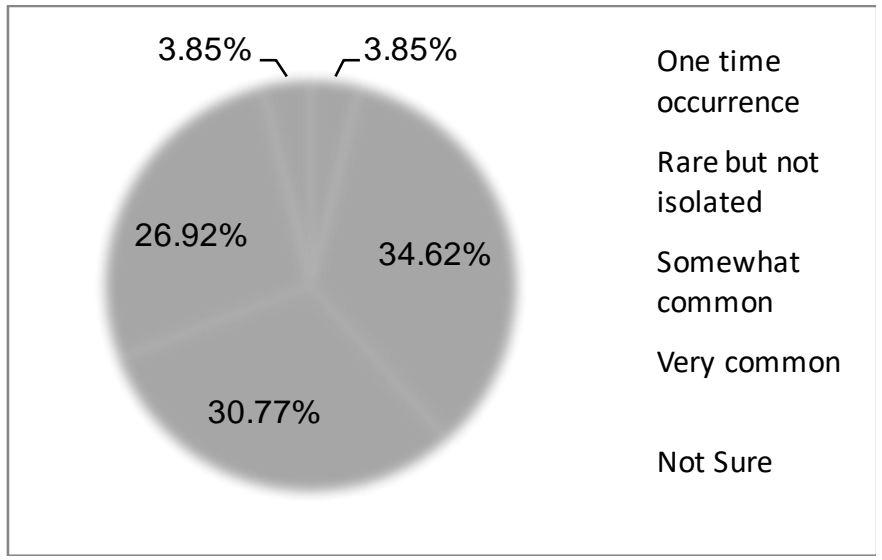

Figure 4 - Participants responses about the 'familiarity' of Hooshmand-1 experiences

\section{$5 \quad$ Recommendations and Conclusions}

The design of this unique simulation game has contributed to ways of learning how to make sense of complex situations and improve the decision-making of senior managers. Although an examination of project portfolio management (PPM) as a function of corporate strategic decision making was a core goal in developing 
Hooshmand-1, the activity can be applied to many kinds of decision-making situations in which there are high level of uncertainty and persistent complexity. Such contexts include urban planning, sustainable energy strategies, capital transport and infrastructure projects, and macro-economic strategies. All these areas have some things in common with the environment created in Hooshmand-1 - including the impact of social factors linked to decision makers' emotions, unintended consequences of inadequate decisions arising from poor use of limited information, confusion about how to handle unknown factors, and variations in technical knowledge occurring during the early stages of planning for mega projects.

The development of Hooshmand-1 demonstrated the application of a positivist approach to learning from failure, rather than merely seeking to identify causes of failure points. The design process embraced creative thinking in its early stages to develop alternatives and collect cues from testing in order to develop a simulation that could be used for research purposes. Such an approach can help designers achieve a robust outcome from their design process. Hooshmand-1 is an environment within which difficult issues concerning decision making are created and framed for discussions which lead to fresh understanding for further analysis. Such discussion can become tools for exploring the kinds of early warnings which can prevent disaster occurring during complex workplace situations. Hoohsmand-1 illustrates how emergence of 'Groupthink' can contribute to ill-formed decisions that created failure for corporations. Hooshmand-1 also demonstrates that identification and acknowledgement of decision makers' emotions, along with effective resolution of them, can help to reduce the negative impact of biased views, and reduce the risk of defective decisions.

\section{References}

1. De Bono, Edward (1991) I Am Right and You Are Wrong, Penguin Books, London

2. Archer, N. P. and F. Ghasemzadeh (1999). "An integrated framework for project portfolio selection." International Journal of Project Management 17(4): 207-216.

3. Engwall, M. and A. Jerbrant (2003). "The resource allocation sydrome: the prime challenge of multi-project management." International Journal of Project Management 21.

4. Hussein, B. A. (2007) On using simulation games as a research tool in project management organizing and learning through gaming and simulation Trondheim

5. Janis, I. L. (1972). Victims of groupthink. Boston, Houghton Mifflin.

6. Janis, I. L. (2016). "Groupthink-Psychological-Studies-of-Policy-Decisionsand-Fiascoes."

7. Kearney, J. W., M. Heffernan and J. McLuckie (2013) "Fleet Doctor To Airpower 2100 - from Tailored Solution to Learning Environment." 
8. Killen, C. P. (2013). "Evaluation of project interdependency visualizations through decision scenario experimentation." International Journal of Project Management $(0)$.

9. Kurtz, C. F. and D. J. Snowden (2003). "The new dynamics of strategy: Sense-making in a complex and complicated world." IBM Systems Journal 42(3): 462-462.

10. Leigh, E. (2012). Short Description of WipWap1 and Airpower2100. S. Shalbafan. Sydney: 1 .

11. Naber, T. and M. van Oort (2005). Master Thesis, University of Tilburg

12. Perković, G. (2014). "Global Crisis Efects On Financial Position And Business Efficiency Of B\&H's Industrial Companies " Sarajevo Business and Economics Review 33.

13. Petit, Y. and B. Hobbs (2010). "Project portfolios in dynamic environments: Sources of uncertainty and sensing mechanisms." Project Management Journal 41(4): 46-58.

14. Project Management Institute, P. (2012). The standard for project portfolio management Third Edition, Project Management Institute.

15. Sa. Silva, P., D. Pedrosa, A. Trigo and J. Varajao (2011). Simulation, Games and Challenges: From Schools to Enterprises. J. Barjis, T. Eldabi and A. Gupta. Berlin, Springer: 63-73.

16. Sardon, G. and S. W. Wong (2010). Making Sense Of Safety: A ComplexityBased Approach To Safety Interventions. Association of Canadian Ergonomists 41st Annual Conference, Kelowna, BC,

17. Shalbafan, S., E. Leigh, J. Pollack and S. Sankaran (2015). Using simulation to create a time-bound, space-constrained context for studying decisionmaking in project portfolio management using the Cynefin framework. Apros - Egos 2015. Sydney.

18. Taleb, N. N. (2007). The Black Swan.

19. Yetive, S. A. (2003). "Groupthink and the gulf crisis." British Journal of Political Science 33. 